\title{
Comments on the Journal of Institute of Science \& Technology (JIST) Vol. 19, No. 2, 2014
}

\author{
Madan Koirala \\ Central Department of Environmental Science \\ Tribhuvan University, Kathmandu \\ E-mail: madankoirala@gmail.com
}

First and foremost, I congratulate the editorial team of Journal of Institute of Science and Technology (Vol. 19, No. 2, 2014) for bringing the publication in this shape. Being in Editorial team, Editor in Chief and Reviewers of various journals, I can understand the pain in the process of bringing out the journal into publication.

I want to appreciate the effort made by Prem Bahadur Budha, author of the first article, who compiled the history of the JIST from its inception, till to date with its problems, challenges and future prospects. I feel, it helps in providing future direction of the journal, enhance the quality and professionalism in scientific world. IOST being the pioneer institution in the field of Science \& Technology of the country also has some responsibility to take lead in publication matter as well. This documentation of the history will help to those who want to pursue further in future days.

In figures, the journal shows the following picture in terms of articles distribution. Out of the total 26 articles by subject 8 represented physical science, 9 biological science, 6 mathematical science and 3 others. By authors, 12 are single authored articles, 8 authored by 2,4 by multiple authors, notes and reviews are of course single authored.

It is an appreciative task of the editorial team to bring 2 volumes of publications in a single year, in a context where research and publications are not the matters of priority. Still, there are some rooms for improvement in the journal. There was an error on pg.1, para. 2, column 2 , line 6 should be " $66^{\text {th }}$ volume in 1976 " instead of " $5^{\text {th }}$ volume in 1973". There is not representation of a single article from out of the country; this shows the limitation in the circulation part. A single author has two or more than 2 papers as co-authored. However, it shows the activeness of those authors, it might exclude the inclusion of others. Majority of the members of the editorial team have articles in this issue. It shows the pro-activeness of them in involving such writing in one hand or it may leave a message that editorial team members are occupying major share of the content of the publication in the other. Following the instructions to authors, it is not a point to give remark, still classification of review, research articles and short communication looks nice what the present volume has made in the form of note at the end of the issue. Though, it is a journal published by an Institute of Science \& Technology, of leading University of Nepal ISSN number is not seen in the pages where it is required. I wish it will go to online version in future days and will be linked with Nepal Journals Online (www. nepjol.info) soon. 